Horacio Cao*

Josefina Vaca**

\title{
Desarrollo regional en la Argentina: la centenaria vigencia de un patrón de asimetría territorial ${ }^{* * *}$
}

\begin{abstract}
Republic or Argentina is characterized by a sharp inequality in the development level of it regions. This paper reviews the way in which that regional asymmetry is originated, and how it was reproduced along the different stages of Argentinean history. A series of hypothesis regarding it main features in the present stage is developed.

Keywords: Regional history, regional development, inequal development, provinces, Argentina.

\section{Resumen}

La República Argentina se caracteriza por la marcada desigualdad en el nivel de desarrollo de las regiones que la componen. En el presente trabajo se pasa revista a la manera en que se origina tal asimetría regional y cómo se fue reproduciendo a lo largo de las distintas etapas de nuestra historia, y se desarrolla una serie de hipótesis acerca de cuáles serían, en la etapa actual, sus principales características.
\end{abstract}

Palabras clave: historia regional, desarrollo regional, desarrollo desigual, provincias, Argentina. 


\section{Introducción}

U no de los elementos que definen a la Argentina como país subdesarrollado, en transición o periférico, es la asimetría en el desarrollo de las regiones que lo componen.

Como se describirá con mayor detalle a lo largo de este trabajo, tal desigualdad territorial tiene su origen en la modalidad de organización asumida en la última etapa del siglo XIX. En tal momento, y a favor de circunstancias económicas, políticas y militares, el emprendimiento agroexportador de base pampeana ocupó el centro de la dinámica nacional, generándose una brecha con el resto de los territorios que nunca pudo cerrarse.

Un solo ejemplo permitirá mostrar la relevancia de esta situación: mientras que en Argentina la diferencia entre las jurisdicciones de mayor y menor Producto Bruto Geográfico per cápita (Ciudad de Buenos Aires vs. Formosa, año 1997 ProvInfo, 2005) es de 11,6 a 1, en Estados Unidos y Canadá, por considerar dos países federales desarrollados, esta diferencia es del orden de 2 a 1 (U.S. Census Bureau, 2003; Statistics Canada, 2003).

A lo largo de la historia del país, las diferencias interregionales ocuparon el interés de políticos, pensadores e investigadores sociales. En el siglo XIX, autores relacionados con el origen de nuestra organización nacional, como Juan Bautista Alberdi o Domingo Faustino Sarmiento, trataron el tema, y en la primera mitad del siglo XX, los principales políticos y muchos de los intelectuales más reconocidos lo consideraron como uno de los desafíos centrales que debía enfrentar nuestro país.

Pasada la mitad del siglo XX, y alrededor del en ese entonces flamante paradigma del desarrollo re-

Centro de Investigaciones en Administración Pública (CIAP), Facultad de Ciencias Económicas de la Universidad de Buenos Aires. E-mail: horaciocao33@hotmail.com

* Centro de Investigaciones en Administración Pública (CIAP), Facultad de Ciencias Económicas de la Universidad de Buenos Aires. E-mail: josefinavaca@yahoo.com.ar

** Recibido el 16 de agosto de 2005, aprobado el 16 de noviembre de 2005 . gional, una serie de investigadores coincidieron en un análisis de las relaciones entre las regiones argentinas llamado a tener amplio consenso entre la comunidad científica. Fue como el vuelo del búho de Minerva; los procesos de ajuste estructural iniciados en la década del ' 70 produjeron la ruptura de los equilibrios que habían sido tan brillantemente descritos.

A propósito de estos hechos, el presente trabajo es parte de los estudios que enfrentan el desafío de construir una representación de los nuevos equilibrios que, como consecuencia de las condiciones sociales, económicas y políticas de las últimas décadas están emergiendo en el territorio argentino. Puntualmente, nuestro objetivo es marcar las continuidades y rupturas que existieron en el desarrollo relativo de las provincias a lo largo de la historia y exponer una hipótesis acerca de su configuración actual.

En este último aspecto, sabemos que se trata de una etapa de transición donde el perfil de especialización y equilibrio espacial todavía tiene contornos borrosos. A pesar de ello, consideramos que la importante cantidad de trabajos referidos al tema conforman una masa crítica lo suficientemente madura como para poder empezar a dar algunas respuestas provisorias. En tal sentido, se quiere senalar que este escrito se sirve y es corolario de diferentes estudios en los que participaron los autores (Cao y Rubins, 1998; Vaca, 2003; Cao, Rubins y Vaca, 2003; Cao, 2006).

En cuanto a los contenidos específicos del trabajo, básicamente están orientados a realizar una presentación estilizada de las líneas y tendencias que caracterizaron los equilibrios regionales del país desde su consolidación como Estado-Nación (segunda mitad del siglo XIX) hasta la actualidad. En función de esta lógica, el texto se divide en tres secciones, cada una de ellas dirigida a analizar la situación de las regiones en las diferentes etapas en que se suele dividir la historia del país.

Para terminar esta introducción se considera conveniente realizar algunas precisiones conceptuales.

La perspectiva de análisis que se adopta, en oposición a lo que puede englobarse bajo el rótulo de 
teorías convencionales del desarrollo ${ }^{1}$, se identifica con el llamado "Estructuralismo Latinoamericano" que postula la especificidad de la situación de los países subdesarrollados y de la coyuntura histórica mundial. En términos generales, puede decirse, además, que la evolución y la transformación de los procesos productivos, de las relaciones de trabajo y de las formas del crecimiento económico, se estudian teniendo en cuenta sus conexiones con las condiciones de vida de la población (Arocena, 2001).

Por otra parte, siguiendo la gran mayoría de trabajos dedicados al tema, tomaremos como unidad de análisis los Estados constituyentes de la federación, que en la actualidad suman 23 provincias y un Estado autónomo (el de la ciudad de Buenos Aires) $)^{2}$.

Ocasionalmente, para referirnos a procesos desarrollados a mayor escala, trabajaremos con una regionalización muy utilizada en la Argentina, que reúne provincias bajo una lógica preponderantemente originada en la geografía física. Esta operación divide al país en cinco unidades: Pampa Húmeda, Patagonia, Noroeste (NOA), Noreste (NEA) y Cuyo.

Finalmente, llamaremos áreas a los agrupamientos de provincias que, en cada caso, tienen un grado de homogeneidad en su nivel de desarrollo y en los que se desenvolvieron procesos históricos relativamente comunes. Con el fin de orientar al lector, en los mapas se presentan las provincias, regiones y áreas que se utilizarán a lo largo del texto.

\footnotetext{
1 Para estas teorías, el desarrollo de un país es el proceso por el cual su capacidad productiva y su estructura económica se van asemejando a las de los países industriales avanzados. Estos enfoques suponen que, en sus notas esenciales, este proceso es el mismo para todas las formaciones nacionales, existiendo etapas por las que la sociedad debe pasar a lo largo de un progreso evolutivo (otro rasgo característico es la identificación del desarrollo con el crecimiento económico).

Si bien los límites geográficos de las provincias no necesariamente coinciden de manera exacta con el espacio al que se le asigna un cierto nivel de desarrollo socioeconómico, los desvíos que en este sentido pueden existir son de tipo marginal, siendo poco relevantes para el grado de generalidad en que se mueve este trabajo.
}

\section{La articulación regional en la etapa de consolidación del Estado-Nación}

Hacia fines del siglo XIX intereses europeos pusieron sus ojos sobre la Pampa Húmeda. Aunque se sabía de larga data que sus tierras eran excepcionalmente aptas para la producción ganadera y agrícola de clima templado, sólo cuando confluyeron una serie de factores externos e internos, pudo comenzar a desarrollarse su potencial productivo.

Entre los factores externos cabe mencionar el auge de las exportaciones de productos primarios hacia los países centrales en curso de acelerada industrialización, la oferta de capitales para la modernización y expansión de las economías exportadoras y una vigorosa ola de inmigrantes venidos principalmente desde el sur de Europa.

En el ámbito interno, interesa destacar la importancia que tuvo la pacificación del país y la consolidación del Estado-Nación, procesos que ingresan en su etapa final con el triunfo militar de la provincia de Buenos Aires sobre el resto del país al que se conoce como el interior (Batalla de Pavón, año 1861). Bajo la supremacía militar y económica de Buenos Aires comenzó a construirse una comunidad de intereses entre actores de las distintas regiones que, entrañando una articulación territorialmente jerarquizada, se tradujo en un pacto interregional implícito. Los elementos fundamentales de este pacto fueron:

\section{En lo político:}

- $\quad$ El interior reconoce la hegemonía de Buenos Aires y se compromete a no poner en juego la estabilidad del sistema.

Buenos Aires reconoce al resto de las clases dominantes provinciales como legítimas representantes territoriales y deja de lado proyectos unitarios o de reemplazo de estas élites regionales.

\section{En lo económico:}

Se organiza un mercado único nacional alrededor del Puerto de Buenos Aires y del emprendimiento agrícola ganadero, lo que implica cortar históricas relaciones entre las regiones derrotadas en la guerra civil y merca- 
Horacio Cao y Josefina Vaca

Mapa 1. Equilibrio entre regiones en la etapa de consolidación del Estado-Nación, fines del siglo XIX-principios del XX.

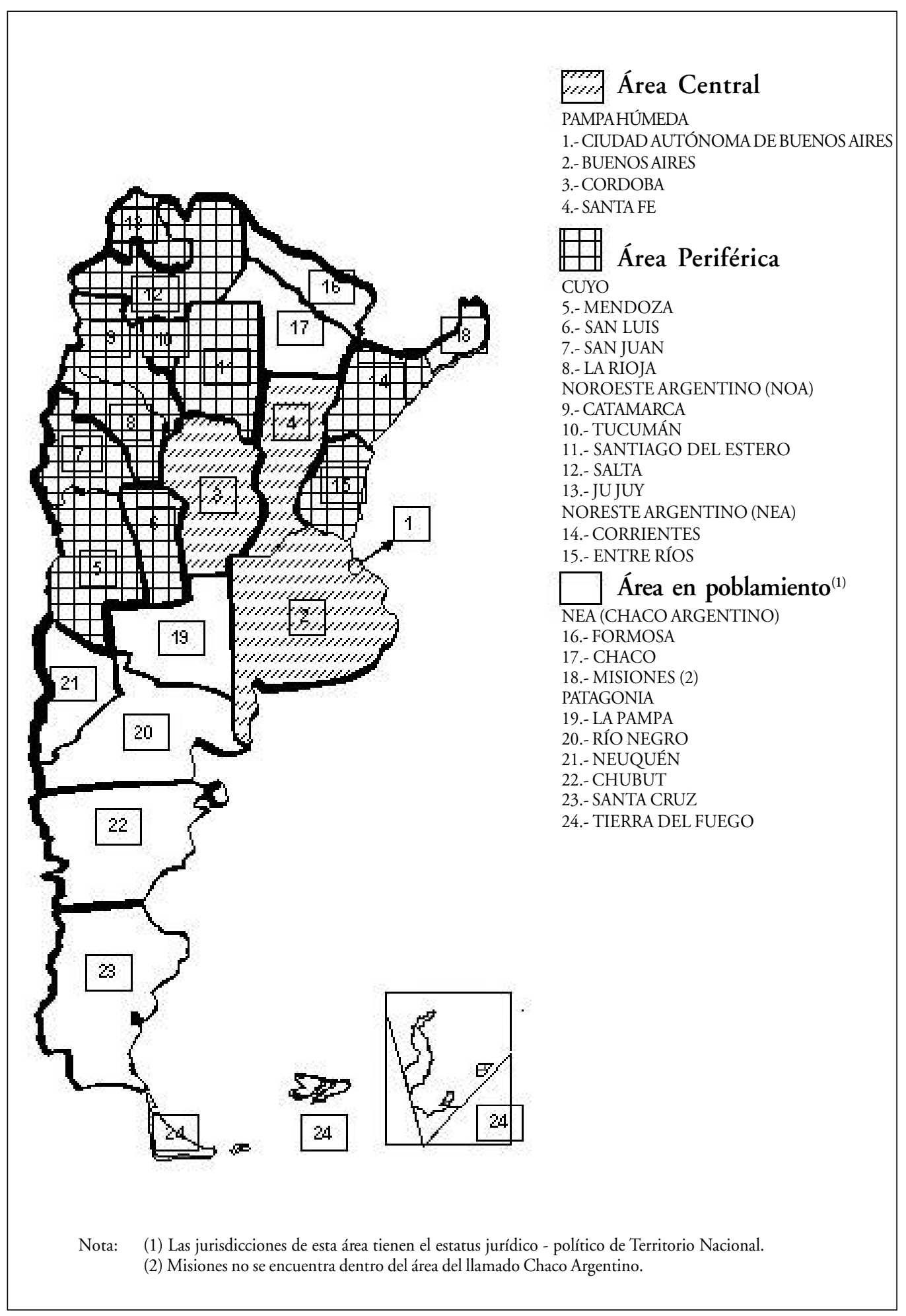


dos que las móviles fronteras de la época habían dejado en países limítrofes (Bolivia, Brasil, Paraguay, Chile).

- El gobierno central, como contrapartida, despliega una serie de "subsidios y auxilios" hacia provincias que se encontraban en una situación económica y fiscal crítica. Paulatinamente, el emprendimiento agrícola ganadero se extiende hacia otras provincias pampeanas, a la vez que comienzan a implementarse políticas públicas que posibilitarán el surgimiento de economías agroindustriales en otros puntos del país ${ }^{3}$.

Este escenario era ventajoso para los actores hegemónicos de Buenos Aires, pues les resultaba conveniente asignar una porción de la renta pampeana a la pacificación del país y a la incorporación de un importante espacio de apoyo a su crecimiento capitalista. Según el Censo de 1895 más del 40\% de la población era parte de lo que se identifica con el área periférica, y aunque la zona sufría una larga crisis, su peso era relevante desde el punto de vista de la oferta de mano de obra, de insumos para la producción, de alimentos para la reproducción de la fuerza de trabajo y de su condición de mercado consumidor.

Asumida la derrota en la guerra civil este acuerdo también era conveniente para las clases tradicionales del interior, en tanto para algunas significaba poder incorporarse al emprendimiento agrícola-ganadero, mientras que para las restantes se abría la posibilidad de una asociación, aunque la misma fuera como miembros subordinados.

En Santa Fe y Córdoba se presentaron las condiciones naturales, socioeconómicas y políticas para sumarse a Buenos Aires en el vigoroso proceso de desarrollo agrícola-ganadero ${ }^{4}$.

Hacia principios del siglo XX, los rendimientos por hectárea de la agricultura argentina eran simila-

3 Los primeros casos fueron los del emprendimiento azucarero en Tucumán y el dirigido a la vitivinicultura en Mendoza. Se trata del inicio de lo que se conocerá como "Economías Regionales", que se describirán en la siguiente sección.

4 En este aspecto es ejemplificadora la situación de Entre Ríos, provincia cuyas condiciones naturales podrían haberle res a los de la norteamericana para el trigo y ligeramente superiores para el maíz y la avena, y obtenía registros equivalentes de productividad para la producción ganadera. Más del $60 \%$ del volumen del mercado mundial en estos rubros tenía origen argentino.

El rápido desarrollo generó en las provincias pampeanas una sociedad más compleja, con estratos sociales diferenciados. Al chacarero, el hacendado y el mercader se le sumó el artesano, el pequeño comerciante y toda una serie de ocupaciones de pequeña burguesía, cobrando importancia la naciente actividad industrial que en los años siguientes tendería a profundizarse.

Fuera de la región pampeana también se produjeron cambios y procesos de modernización significativos. Hubo un creciente involucramiento del Estado Nacional, lo que posibilitó, entre otras cosas, la llegada del ferrocarril a casi todas las provincias. Cabe acotar que, como parte del pacto implícito, la forma federal del gobierno les permitía incidir -en tensión con otros actores regionales- en las políticas que iba desarrollando el naciente Estado-Nación. De todas formas, la dinámica socioeconómica en estas jurisdicciones (Corrientes, Entre Ríos, Salta, Jujuy, Santiago del Estero, San Juan, San Luis, Mendoza, La Rioja, Catamarca y Tucumán) se desplegó a un ritmo que implicó un indudable rezago frente al notable desenvolvimiento pampeano.

El tercer vector bajo análisis se refiere a los últimos territorios que, dentro de los límites de la República, se mantenían en manos de población aborigen. El proceso de ocupación e institucionalización que tuvo como escenario la región Patagónica en el sur y el Chaco Argentino en el noreste (ver mapa 1), incrementó la superficie del territorio en casi un 60\%. Resulta indudable que la incorporación de un área geográfica tan inmensa fue posible por la pacificación del país y por el desarrollo económico que per-

facilitado el desarrollo de procesos similares a los descritos. Su rezago relativo se habría debido a la cercanía de los mercados brasileños de tasajo (carne salada para alimento de esclavos), que le permitió a esta provincia mantener sus tradicionales estructuras ganaderas sin apelar a la diversificación del agro que, en una primera etapa, fue el elemento que motorizó la transformación económica. Ver al respecto Gorostegui de Torres (1992). 


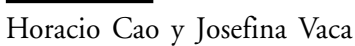

Mapa 2. Equilibrio entre regiones en la etapa ISI, mediados del siglo XX.

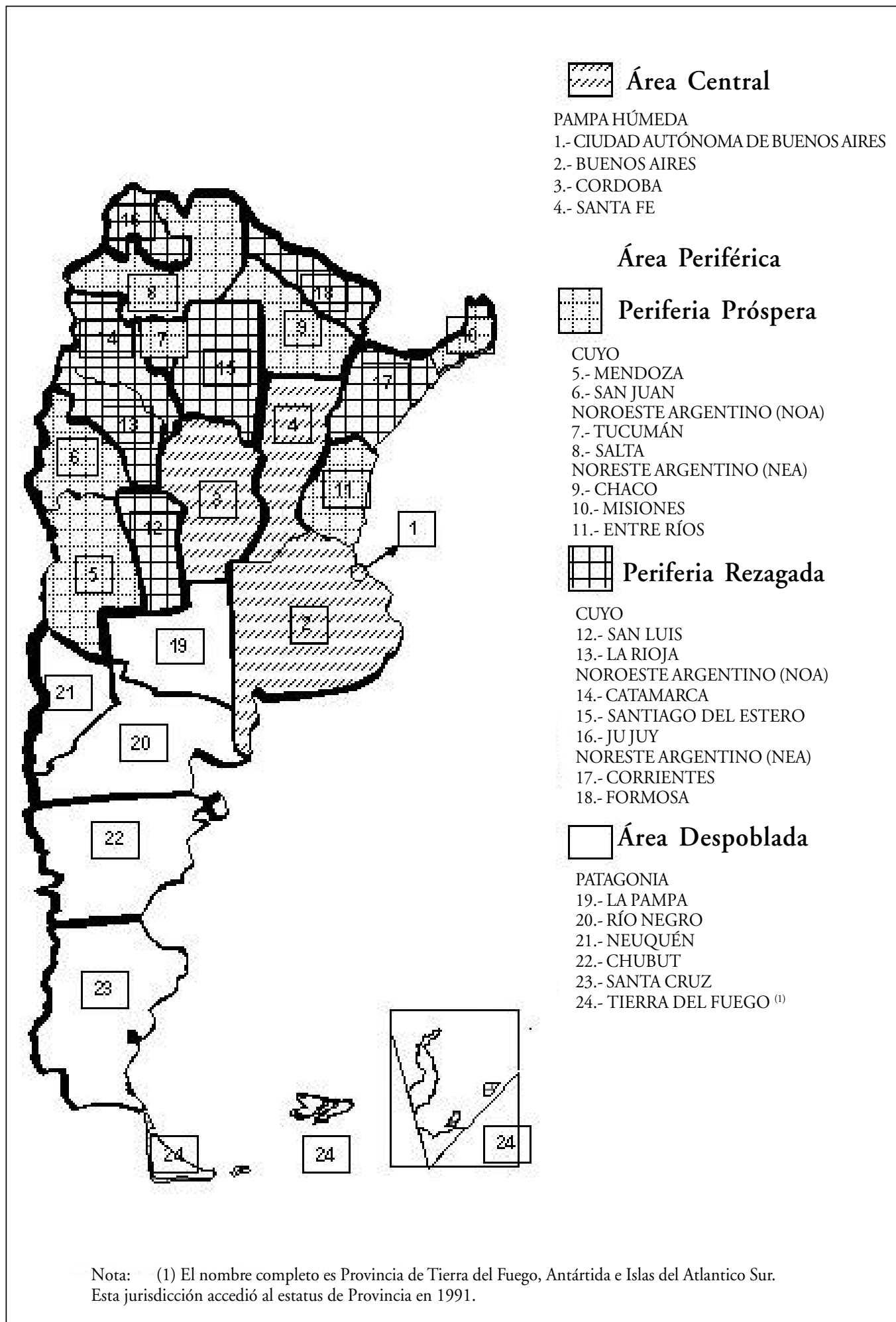


mitió el financiamiento de las expediciones de ocupación y poblamiento.

Los espacios así incorporados fueron administrados bajo el estatus jurídico de "Territorios Nacionales", que le daban una dependencia política y administrativa directa con el gobierno central. En el sur se conformaron los Territorios Nacionales de La Pampa, Neuquén, Río Negro, Chubut, Santa Cruz y Tierra del Fuego, mientras que en el noreste los de Chaco, Formosa y Misiones.

El proceso de incorporación efectiva de estos espacios a la órbita nacional involucró tareas de ocupación militar y el despliegue de las primeras estructuras económicas que, en el caso del área del Chaco argentino, se circunscribieron al aprovechamiento del bosque nativo para la producción de durmientes de ferrocarril, estacas para alambrados y curtiente tintóreo.

En la región patagónica, por su parte, se comienza con el desarrollo de una ganadería extensiva, centrada en la producción de lana, carne ovina, cueros y pieles para exportar. Para dar una imagen de la situación, digamos que durante la primera década del siglo XX, en lo que luego sería la Provincia de Santa Cruz (casi $250.000 \mathrm{~km} 2$ ), menos de diez mil personas, entre otras tareas, criaban 11 millones de ovejas (Secretaría de Agricultura, Ganadería y Pesca, 1990).

En resumen, en esta etapa histórica, el equilibrio interregional argentino se encuentra caracterizado por contener una típica estructura centro-periferia, donde ésta última tiene como principal tarea apoyar los procesos que se desenvuelven en el centro, encargado por su parte de garantizar la articulación con el mercado mundial y la integridad de todo el sistema. Adicionalmente, se realiza la incorporación efectiva de extensos territorios, surgiendo así un tercer espacio, con características diferenciadas.

\section{La crisis del '30 y la recomposición bajo un nuevo patrón productivo}

La crisis iniciada hacia 1930 provocó profundos cambios en la economía mundial. En el caso de la Argentina, el papel central del sector externo hizo que la caída de los precios internacionales y la expansión de las barreras proteccionistas en los principales mercados donde se dirigían sus productos pusieran en riesgo todo el ordenamiento productivo nacional.
Como respuesta a la crisis en nuestro país se inicia un proceso de industrialización por sustitución de importaciones (en adelante ISI), que se vio favorecido en sus inicios por la dimensión que había alcanzado el mercado interno y por la presencia de mano de obra proveniente de las migraciones.

La etapa de vigencia de la ISI se caracterizó por presentar tasas de crecimiento económico relativamente estables e importantes en particular durante el periodo 1952-1970, en que el PBI por habitante creció a una tasa superior al $4 \%$. Dentro de este importante dinamismo se destaca la perfomance del sector industrial, cuya participación en el PBI se incrementó del 23,8\% en 1929 al 35,7\% en el año 1970 (OECEI, 1974). Cabe destacar que entre 1914 y 1970 el perfil de la sociedad argentina sufre una profunda transformación; por ejemplo, la población se multiplica por tres, y en su gran mayoría (casi el 80\%) habita en centros urbanos; el analfabetismo baja del $36 \%$ al $8,4 \%$ y la matrícula de las Universidades pasa de 20.000 alumnos en 1930 a más de 230.000 en 1970 (ProvInfo, 2005; OECEI, 1974).

Sin embargo, estos procesos de indudable importancia en la esfera política, social y económica del país, sólo implicaron modificaciones menores en el posicionamiento relativo de las provincias. Una serie de análisis lograron amplio consenso en dividir el territorio nacional en tres áreas: Central, Periférica y Despoblada ${ }^{5}$. A grandes rasgos, las principales características de estas áreas eran:

Provincias del Área Central: Posicionada en el centro-este del país, comprende las provincias de Buenos Aires, Santa Fe, Córdoba y la Capital Federal (Ciudad de Buenos Aires). Fue el área dondecomo en la etapa anterior- se desarrolló la producción de granos (trigo, maíz, cebada, alfalfa y más tardíamente soja) y de ganado. Los excedentes producidos por estos emprendimientos fueron, en gran medida, aplicados al financiamiento de las políticas ISI, que se localizó principalmente en estas provincias. Como resultado de esta situación, el área central

5 Nos referimos a los clásicos trabajos de Rofman y Romero (1997), Ferrer (1980) y Núñez (1974). Estas clasificaciones difieren en sus enfoques y marginalmente en algunos de sus resultados, pero básicamente siguen la lógica descrita en este trabajo. 
se distingue por una concentración de población y un aparato productivo de dimensiones muy superiores y características más modernas que el observado en otras regiones del país.

La industria-que como vimos, fue el segmento más dinámico del período- tuvo su centro en las principales conurbaciones de esta área, situación originada en que el patrón territorial de la ISI se definió en sus primeras etapas, cuando la sustitución se realizaba sobre las industrias livianas. En estos casos, de no mediar políticas expresas, la localización se define en función de la proximidad y magnitud del mercado consumidor, teniendo una influencia de menor relevancia la ubicación de las fuentes de materias primas. A esto debe agregarse que el área central presentaba ventajas relativas a partir de la calidad de su infraestructura, tamaño de su mercado, stock de capital humano calificado, presencia de puertos para abaratar el abastecimiento de materias primas importadas (Buenos Aires y Rosario), etc. Considerando promedios de datos censales (Censo Industrial de 1954 y Censos Económicos de 1963 y 1974), más del $80 \%$ de la mano de obra industrial se concentró en las cuatro jurisdicciones del área central.

Provincias del Área Periférica: Comprendida por las provincias de la franja noreste, norte y centrooeste del país, se distinguen por su bajo desarrollo relativo, sus indicadores de deterioro social y una aguda dependencia del sector público.

En la economía de estas provincias tienen una importancia cardinal las llamadas "economías regionales". Se trata de una serie de emprendimientos agroindustriales caracterizados por orientarse hacia el mercado interno y por asumir, en casi todos los casos, el carácter de monoproducción provincial. Sus ejemplos más emblemáticos son los de la producción de azúcar y tabaco (Tucumán, Salta y Jujuy), vitivinicultura (Mendoza y San Juan), algodón (Chaco y Formosa), yerba mate y té (Corrientes y Misiones), etc.

Como vimos, los primeros antecedentes de las economías regionales tuvieron su origen hacia fines del siglo XIX, observándose a partir de 1930 una profundización de las tendencias que, en casi todos los casos, ya se encontraban en desarrollo. Como han hecho notar diferentes autores (Balán, 1978;
Rofman y Romero, 1997), estas economías surgen a partir de políticas concretas de la Administración Federal (protección aduanera, subsidios, construcción de ferrocarriles, etc.), y sólo pueden entenderse en el marco de la incorporación de grupos dominantes extrapampeanos al citado pacto interregional implícito.

Los instrumentos utilizados para el desarrollo de las economías regionales - tanto los destinados a evitar crisis de sobreproducción (establecimiento de cupos productivos, limitación del área sembrada) como los que garantizaban un piso de ganancias a los pequeños productores (precios sostén)- fueron consolidando una estructura productiva caracterizada por una penetración irregular de relaciones de producción capitalistas y un quietismo en la política regional que le era consecuente.

$\mathrm{Al}$ amparo de la intervención estatal se organizó una forma de tenencia de la tierra, que combinaba minifundios y latifundios en continua regeneración. Los primeros, como fruto de las garantías que se otorgaban para la supervivencia de pequeños campesinos; los segundos, como forma de optimizar ganancias extraordinarias que no se originaban en la incorporación de adelantos tecnológicos, sino en las condiciones de privilegio que garantizaba el Estado. Ambos polos de la escala productiva tuvieron incentivos para exportar la conflictividad de la sociedad regional hacia el ámbito nacional: era de interés común lograr el máximo provecho de las regulaciones que, en competencia con otros actores regionales, se dirimían en el gobierno central.

Las ventajas económicas que ofrecía esta situación hicieron que en torno de las economías regionales se entrelazaran los tradicionales actores locales con otros de origen pampeano, y también con inversores internacionales ${ }^{6}$. El poder relativo de este conglo-

6 En el caso de la producción azucarera, la apertura en la ciudad de Rosario (Santa Fe) de una refinería que por su escala y modernidad fue monopólica por un largo periodo, hizo las veces de catalizador para terminar uniendo todos estos intereses. En efecto, la producción de caña articulaba terratenientes tucumanos con capitales ingleses y suizos. El azúcar cruda atravesaba medio país en ferrocarriles ingleses. El ingenio azucarero era de Tornquist, representante típico de la alianza de Europa con los intereses del puerto de Buenos Aires (Balán, 1978). 
merado explica, en buena medida, el importante nivel de subsidios, obra pública nacional y protección arancelaria desarrollada por el Estado Central.

Dentro de este grupo de provincias, algunos trabajos diferencian dos subconjuntos:

- Provincias de la periferia próspera: aquellas donde las economías regionales ocuparon un lugar central dentro del aparato productivo provincial logrando, a través de su dinamismo, un crecimiento apreciable y la generación de los empleos necesarios como para evitar migraciones masivas de su población. Se trata de las provincias de Tucumán, Salta, San Juan, Mendoza, Misiones, Chaco y Entre Ríos ${ }^{7}$.

- Provincias de la periferia rezagada: aquellas provincias donde el despliegue de las economías regionales tuvo una importancia secundaria frente al peso de las actividades rurales de neta subsistencia o del accionar de la Administración Pública. Estas jurisdicciones se caracterizan, además, por las corrientes migratorias hacia las áreas centrales y el deterioro en la participación relativa en el PBI. Involucra las jurisdicciones de Catamarca, La Rioja, Santiago del Estero, Formosa, Corrientes, San Luis y Jujuy.

Área Despoblada: Ubicada en el extremo sur del territorio, en lo que se conoce como Patagonia argentina, comprende las provincias de Río Negro, La Pampa, Neuquén, Chubut, Santa Cruz y el en ese entonces Territorio Nacional de Tierra del Fuego. Estas provincias se distinguen por una baja densidad poblacional, fruto del tardío proceso de ocupación y desplazamiento de la población aborigen. Como consecuencia de esta situación, su desenvolvimiento económico-social se encuentra cardinalmente influido por políticas de poblamiento, como fueron las de fijación de grandes contingentes de personal de las Fuerzas Armadas, por regímenes preferenciales de producción y una inversión pública en infraestructura económica y social per cápita superior a la que se observa en el resto del país.

\footnotetext{
7 Dentro de este grupo, Entre Ríos ocupaba un lugar especial, ya que su potencial económico no se basaba en una "economía regional" sino en un desarrollo agro-ganadero de características diferenciadas con respecto al del área central.
}

Es de destacar que estas políticas tienen su razón de ser en la percepción -no importa aquí si acertada o no-de que la Patagonia podía perderse como parte del territorio nacional. Esto marcó diferencias significativas entre la forma en que fue ocupado este territorio y lo que ocurrió en otras áreas del país, en particular, en la del Chaco argentino, que también fue colonizada tardíamente. A diferencia de lo que ocurrió en la Patagonia, en las jurisdicciones de Chaco, Misiones y Formosa se desarrollaron típicas economías regionales (yerba mate, té, algodón), con características similares a las que se observan en el resto del área periférica ${ }^{8}$.

Las características demográficas que describimos, unidas a las peculiaridades de la geografía patagónica -clima semidesértico, cobertura vegetal natural enjuta y esparcida, pocos ríos alóctonos- hicieron que casi el 80\% del territorio se dedicara a una cría extensiva de ovejas. Si bien el plantel lanar patagónico -unas 17 millones de cabezas- era importante en el cuadro de la economía argentina a partir de las divisas que generaban las exportaciones de lana sucia, su impronta como factor de crecimiento, poblamiento, inversión y bienestar del ámbito regional era de muy escasa trascendencia (Daus, 1975).

Paralelamente, y al amparo de regulaciones similares a las que habían permitido el surgimiento de las economías regionales, comienza a madurar una agricultura intensiva en torno a los escasos oasis patagónicos. Entre ellos, se destacaba nítidamente el del Alto Valle del Río Negro en la provincia homónima, especializado en la producción de frutas de pepita.

Otro de los hechos importantes de esta etapa fue la consolidación de los emprendimientos ligados a la explotación de carburos -petróleo, gas y carbónque fueran operados hasta 1990 por Empresas Estatales (YPF, YCF y Gas del Estado).

La explotación de estos recursos por parte del Estado permitió la constitución de emprendimientos mineros, en cuyo desarrollo fue notoria la influencia

8 La asimilación entre estas provincias y las de la periferia "histórica" es tan completa que las diferentes clasificaciones de provincias consideran a ambas como parte de las mismas categorías. Ver al respecto Cao, Rubins y Vaca (2003). 
Horacio Cao y Josefina Vaca

Gráfico 1. Índice de Desarrollo Humano en el territorio argentino, (2001).

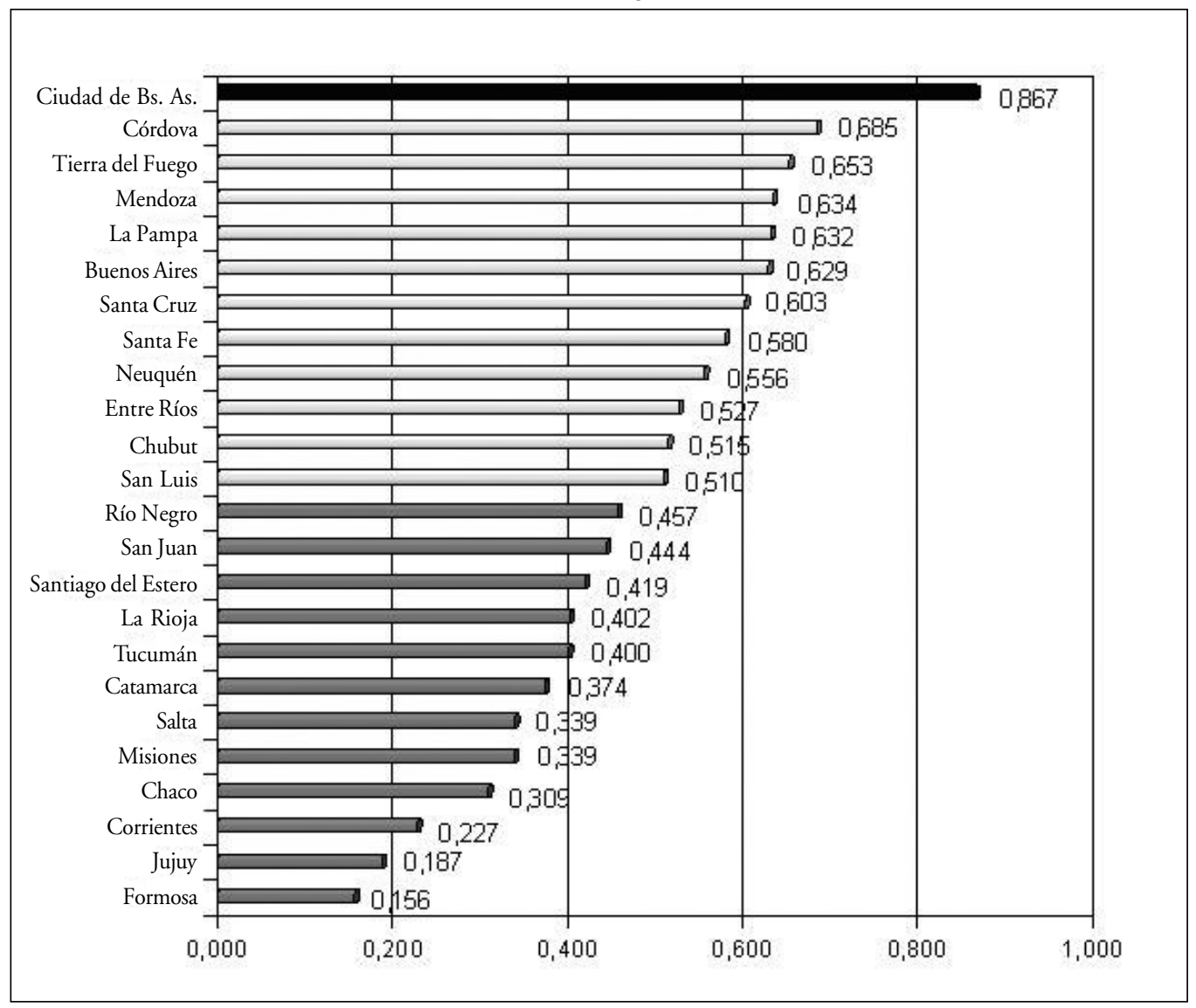

de políticas dirigidas a fomentar el asentamiento poblacional en la Patagonia. Rofman (1999: 99), refiriéndose específicamente a YPF, señala: "La modalidad de ocupación del territorio no se circunscribía sólo a la explotación del recurso natural, sino que abarcaba una amplia red de equipamientos sociales, culturales, recreacionales y residenciales para el personal permanente. Ello implicaba una estrategia de desarrollo urbano y regional que excedía, en mucho, lo que una empresa tipo estaba obligada a realizar en términos de sus objetivos de obtención de la máxima tasa de ganancia posible. De algún modo, YPF 'subsidiaba' al territorio local donde se asentaba y tal decisión superaba una visión mercantilista de su rol y su función como empresa líder en el proceso de extracción, industrialización y comercialización del petróleo".

Para terminar esta sección, es importante mencionar que hacia la década del '50 los Territorios
Nacionales pasaron a tener el estatus de provincias? Esta transformación significó un reconocimiento a la madurez y peso que habían alcanzado los actores sociales territorianos en el mapa político nacional.

\section{El ajuste estructural}

Los cambios que se producen en el país y en el mundo desde mediados de los '70 abren una nueva etapa para las diferentes regiones que componen la República Argentina.

Dentro de las mutaciones que tienen lugar en el ámbito de la política económica, nos interesa destacar el proceso de desmonte de la red de regulaciones que garantizaban un lugar en la economía nacional

9 Con la única excepción de Tierra del Fuego, Antártida Argentina e Islas del Atlántico Sur, que fuera provincializado recién en el año 1991. 
Mapa 3. Equilibrio entre regiones en la etapa del Ajuste Estructural, fines del siglo XX.

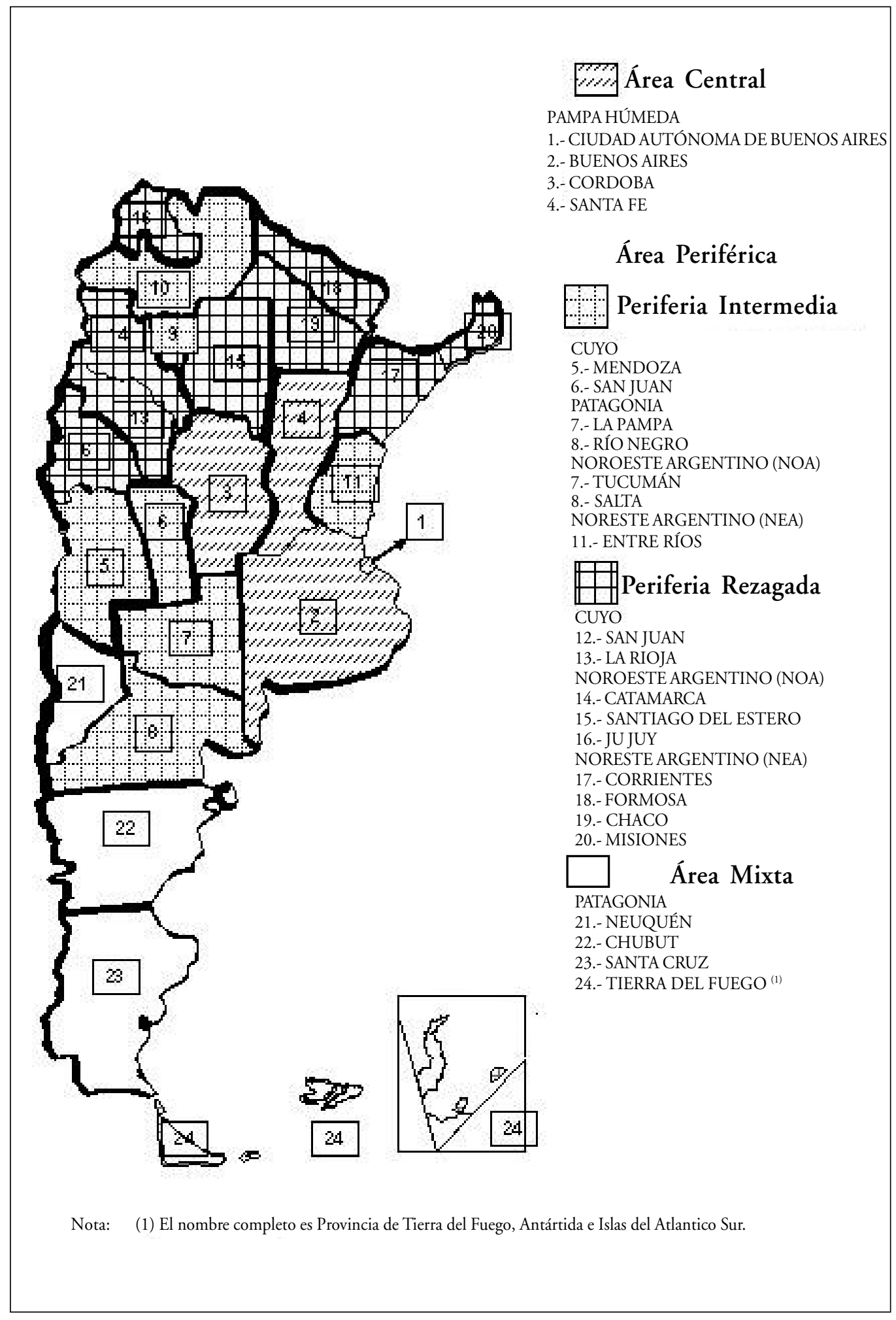


para actores regionales de todas las latitudes ${ }^{10}$. Subyace a estas medidas un cambio en el modo de concebir el espacio geográfico. Como vimos, la configuración de las diferentes regiones fue parte de un proceso de ocupación y colonización de todo el ámbito nacional que se realizó a partir de un modelo global de territorio subsidiado, idea desplazada por el concepto de territorio eficiente. Bajo esta nueva concepción las decisiones son tomadas en razón de la tasa de retorno, lo que obviamente produce modificaciones en el mapa productivo (Yanes, 1998).

Si bien las transformaciones afectan fundamentalmente a los trabajadores (disminución en la participación del ingreso, desocupación, precarización del empleo, etc.) y a los segmentos más débiles de las cadenas productivas (PyMEs, minifundios), en el análisis que nos ocupa es importante remarcar el proceso de renovación que se da en la cúpula económica, donde pierden peso actores de importante impronta territorial. En este sentido es de destacar la decadencia de los actores ligados al proceso ISI, a las economías regionales y a las empresas estatales, como así también el creciente poder de aquellos vinculados a los servicios financieros y el relanzamiento del complejo agrícola de la Pampa Húmeda ${ }^{11}$.

Aunque los perfiles del nuevo equilibrio entre regiones no están totalmente delineados, siendo varios de sus elementos fruto de controversia entre especialistas e investigadores, todo parece indicar que aún se mantienen los elementos que llevaron a agrupar el territorio en tres grandes áreas.

Para corroborar esta afirmación, comencemos diciendo que existen varios estudios de base

10 Algunas políticas de promoción que surgen posteriormente -promoción minera, promoción industrial diferimentos impositivos, etc.- fueron parte de la política global de seducción al gran capital, más que una forma de incorporar a los actores sociales agredidos por el ajuste, y sus resultados fueron enclaves con muy bajo encadenamiento regional.

11 Contra lo usualmente considerado, este recambio no sólo ocurrió en las conurbaciones del centro, que como vimos habían monopolizado los procesos de la ISI, sino que también se verifica en la periferia con el retiro o reformulación de la localización territorial de los grandes grupos empresarios como Massuh, Ledesma, Peñaflor, Zorroaquín, etc. (Rofman y Romero, 1997). econométrica que confirman que, en el mediano plazo, las diferencias en el nivel de desarrollo de las áreas persisten e inclusive pueden llegar a estar incrementándose (Bolsa de Comercio de Córdoba, 1998; Porto, 1995; Willington, 1998; etc.). De igual manera, si se analizan indicadores básicos que reflejan la situación de las diferentes jurisdicciones y áreas que integran el territorio, se arriba a conclusiones similares. En el siguiente gráfico se puede observar el nivel de desarrollo humano (IDH) de las 24 jurisdicciones.

Más allá de la continuidad que se observa en lo que hace a las diferencias en el nivel de desarrollo relativo de las provincias y áreas que integran el territorio, y reconociendo el carácter provisorio de los razonamientos que se expondrán, todo parece indicar que existen algunos cambios de tipo secundario en la conformación de los diferentes agrupamientos de provincias. En este sentido, sobre la base de un estudio realizado por el PNUD $(2002)^{12}$ describiremos, en un nivel de hipótesis, lo que se cree es el nuevo equilibrio regional emergente a partir del ajuste estructural.

En las provincias del Área Central, si bien mantienen su conformación histórica, distinguimos dos estamentos:

- La ciudad de Buenos Aires, única componente de la categoría "economía urbana de servicios", que se caracteriza por la competitividad y dinámica de su economía, por su característica urbana y esencialmente productora de servicios y por ser la única jurisdicción con nivel de Desarrollo Humano Alto (PNUD, 2002).

- Las provincias de Buenos Aires, Córdoba y Santa Fe, componentes de la categoría "estructuras económicas de gran tamaño y diversificadas". En estas jurisdicciones se concentran el grueso de las exportaciones nacionales, las inversiones en sectores manufactureros, la banca y la dinámica financiera. Estas

12 Nos referimos al Informe sobre Desarrollo Humano de la Argentina, que incluye diferentes estudios e índices sobre los desequilibrios interregionales, que se resumen en el Índice de Desarrollo Humano Ampliado y el estudio de la competitividad provincial. 
jurisdicciones tienen un nivel de desarrollo humano medio.

En cuanto a los efectos de las políticas de ajuste estructural en esta área, en el marco de una creciente polarización social y concentración de la producción y del ingreso, se observa un comportamiento dispar, con sectores económicos que presentan un crecimiento espectacular, mientas que otros ingresan en una acelerada decadencia.

Dentro de los sectores desfavorecidos se encuentra el sector fabril, que reduce su participación en el producto del área en casi 10 puntos, pasando del 34,9\% en 1974 al 25,5\% en 1997 (ProvInfo, 2005). De todas formas, algunas fracciones industriales presentan una importante dinámica, como los que se sustentan en la explotación de ventajas comparativas naturales (alimentos y bebidas ${ }^{13}$, y en menor medida, refinamiento de petróleo) y los que aprovechan regímenes especiales de promoción y producción (por ejemplo, el de la producción automotriz). Este proceso se da en el marco de una aguda concentración en donde el 50\% del valor agregado es explicado por apenas cien empresas (Kulfas y Schorr, 2001).

Simétricamente al deterioro de la industria, se observa el crecimiento de importantes segmentos del sector servicios, como por ejemplo el financiero, cuya participación en la sumatoria de los PBG de las provincias del Áreas Central va, en los años citados, del 9,8\% al 23,8\% (ProvInfo, 2005).

Por último, es importante destacar que, desde principios de los ' 70 , se observa el relanzamiento de la tradicional producción cerealera que por varias décadas se había mantenido estancada. Como reflejo de esta situación, si comparamos los promedios quinquenales de exportación de granos entre los años 1970-1974 y los años 1993-1997 se evidencia un incremento cercano al 200\% (de 10 millones a 28 millones de toneladas -Bolsa de Cereales, 1999).

Las provincias del Área Mixta las consideraremos conformadas por las provincias patagónicas con

13 Dentro de este segmento se destacan algunas agroindustrias, en especial la dirigida a la producción de aceite de soja, uno de los principales productos que nuestro país coloca en el exterior. excepción de Río Negro, asimilando esta categoría a la que el PNUD denomina "estructuras productivas basadas en uso intensivo de recursos no renovables" (PNDU, 2002, p. 136).

Chubut, Neuquén, Santa Cruz y Tierra del Fuego se distinguen "por su alto producto per cápita, la importancia de la explotación de hidrocarburos, la elevada participación de las exportaciones en el producto geográfico local y per cápita, y por concentrar las principales inversiones recientes en los sectores energéticos" (PNUD, 2002, p. 138). Aunque estas provincias siguen presentando una baja densidad poblacional relativa, en este registro se acercan cada vez más a la situación de las periféricas, por el doble efecto de ser las provincias del área mixta atractoras y las de la periferia emisoras de población. Cabe aclarar que el carácter "mixto" con el que se denomina a esta área refiere a la superposición de dos tipos de procesos socioeconómicos, los que pueden emparentarse, respectivamente, con los que ocurren en el Área Central y en el Área Periférica.

En virtud de su impacto en las políticas que se desarrollan en esta etapa, un elemento a resaltar es el cambio en la percepción de la situación de las fronteras en el área. En efecto, a partir de la recuperación constitucional de 1983, luego de que las dictaduras militares que gobernaban ambos países pusieran a la Argentina al borde de la guerra con la República de Chile (años 1978-1980), las tensiones con el país trasandino descendieron de manera continuada. Esta situación, unida a la crisis fiscal, redundó en una reducción notable de la vigencia de las políticas de defensa y poblamiento que tanta influencia tuvieran en el pasado.

El cambio de concepción en estas políticas fue uno de los factores que facilitó las privatizaciones de Yacimientos Petrolíferos Fiscales (YPF), Gas del Estado y Yacimientos Carboníferos Fiscales (YCF), a partir de lo cual se observa una situación paradójica; por un lado se verifica un importante aumento de la producción (por ejemplo, la extracción de hidrocarburos se incrementó de 1993 a 1998 en más de un $40 \%$ ), mientras que por otro se reduce drásticamente la porción de la renta carburífera reinvertida en la región. Bajo la nueva administración privada se descarta toda orientación destinada a preservar el perfil poblador y social que previamente identificara el 
desempeño de las empresas estatales. De esta manera, los oasis mineros pasan a ser "enclaves exportadores de recursos naturales [...] colocaciones externas basadas en ampliación de capacidades extractivas que no solamente no procesan la materia prima en el ámbito local, sino que se apropian de los excedentes sin volcarlos en el circuito productivo regional" (Rofman, 1999, p. 95) ${ }^{14}$.

Otro aspecto significativo está dado por la crisis de la explotación ovino-ganadera, originada en la utilización irracional de los recursos naturales (que implica un agudo proceso de desertificación), la crisis de los mercados externos de lana, la parcelación antieconómica de las grandes estancias y el fin de las políticas de promoción que había sostenido el Estado Nacional. Como fruto de esta combinación de factores han desaparecido una gran cantidad de pequeños y medianos productores, al mismo tiempo que se observa una renovada concentración de tierras de la mejor calidad en grandes estancias a cargo de sociedades anónimas y capitales multinacionales, como por ejemplo Pérez Companc y Benetton (Salvia, 1997).

Por último, no podemos dejar de mencionar la importante expansión del emprendimiento turístico dirigido a viajantes de altos ingresos que generó una importante corriente de inversiones y consumo. Sin considerar la ciudad de Buenos Aires, en esta área se percibe la mayor oferta (en términos per cápita) de hoteles de máxima categoría, así como también los periodos más largos de vacaciones en los viajantes y la mayor cantidad de turistas que se alojan en hoteles de cuatro y cinco estrellas (INDEC, 1997).

En cuanto a las Provincias del Área Periférica, las mismas no sólo mantienen su situación de rezago sino que, por tratarse de los espacios más débiles de la configuración territorial del país, en muchos casos sufren un deterioro socioeconómico proporcionalmente mayor al que se observa en otras áreas. En cuanto al impacto del ajuste estructural sobre la situación de estas provincias, se destacan los siguientes fenómenos:

a) La desestructuración del sistema de regulaciones, la crisis de demanda por la reducción de

14 Se estima que esta apropiación de excedentes es, en la Provincia de Santa Cruz, del orden del 25\% de su PBG (Rofman, 1999). ingresos de los asalariados y la apertura a la introducción de bienes competitivos desde el exterior induce una crisis sin precedente en las economías regionales ${ }^{15}$. Como indicadores de esta crisis suele citarse la desaparición del 35\% de las unidades productivas entre los Censos Agropecuarios 1969-2002, y la reducción del $40 \%$ de la mano de obra rural utilizada entre los Censos Agropecuarios 1969-1988.

b) Los ejemplos exitosos de reconversión económica, como la incorporación de Áreas Periféricas a la producción de soja y el desarrollo de una minería metalífera que ha movilizado inversiones multimillonarias, se han desarrollado con bajo encadenamiento con el aparato productivo regional, no teniendo un papel relevante en los circuitos económicos que involucran al grueso de la población. Los cambios en la producción agrícola han tenido amplios efectos sobre la vida provincial. El terrateniente, figura central del ordenamiento tradicional y paternalista de la sociedad provincial, ha sido reemplazado por el productor internacionalizado que a veces ni conoce el campo donde ha invertido, y el peón rural fue suplantado por la cuadrilla. Así, los agentes dinámicos del mundo rural pasaron a estar compuestos en casi todos los casos por población de origen urbano, que va al campo más o menos asiduamente, pero que por lo general, vuelve cotidianamente a sus hogares en la ciudad.

c) La estabilidad constitucional revalorizó las instituciones de cuño federal, lo que permitió a estas provincias recuperar un ámbito donde discutir las políticas nacionales. Las condiciones en que esto ocurre (esquematizadas en los dos párrafos anteriores) hace que estas recobradas potestades sean utilizadas casi exclusi-

15 Durante el periodo fueron perdiendo poder y finalmente se disolvieron los organismos que lideraban los sistemas regulatorios de las economías regionales (Dirección Nacional de Azúcar, Comisión Reguladora de la Comercialización de Yerba Mate, Comisión Reguladora de la Producción Vitivinícola, etc.), así como también se privatizaron o liquidaron empresas estatales que eran pilares en su reproducción (Cavic, Giol, Las Palmas, Compañía Nacional Azucarera S.A., etc.). 
vamente para conseguir transferencias de recursos por parte de la Nación. Como contrapartida, los representantes de cada una de estas provincias tienden a funcionar como aliados del gobierno nacional. Es la nueva versión del pacto regional implícito.

d) Con los recursos así obtenidos, se financia un importante incremento en el peso de la Administración Pública en el funcionamiento de los diferentes circuitos económicos y sociales. A través de sostener a casi la mitad del empleo asalariado, una masa proporcionalmente importante de jubilados y pensionados y por medio del gasto en obra pública y en bienes y servicios no personales, funge como garante de un cierto nivel de actividad, empleo y demanda agregada. En suma, a través de un proceso que Cao denomina (2003) ajuste pasivo, el gasto público reemplaza a las economías regionales como principal elemento del aparato productivo ${ }^{16}$.

Dentro de este grupo de provincias, siguiendo la modalidad de trabajo utilizada para analizar el periodo anterior, diferenciaremos dos subconjuntos:

\section{Las Provincias Periféricas Intermedias:}

a) Río Negro, Entre Ríos, Tucumán, Salta y La Pampa $^{17}$, que se caracterizan por conformar un segmento en el que a las producciones tradicionales e históricas se le han ido agregando nuevos rubros de base agraria. Allí se registran inversiones de grandes empresas pero en forma muy selectiva y sectorialmente concentrada.

b) Mendoza, provincia que se considera ocupa un lugar de transición entre este grupo y el del área central ${ }^{18}$.

16 En la etapa ISI, la participación del sector público -preponderantemente de jurisdicción nacional- tenía otro carácter: el de sostener la producción de las economías regionales reemplazando (cuando era necesario) la acción de ciertos actores sociales que no surgían espontáneamente del mercado.

17 A pesar de que la definición de la categoría es apropiada para definir la situación de la provincia de La Pampa, muchos de sus indicadores se emparentan más con los que se observan en el área mixta.

18 Si bien Mendoza puede ser incorporada al Área Central, esta provincia tiene una dimensión muy inferior al c) San Luis, que se distingue por presentar un dinámico proceso de radicaciones industriales basadas originalmente en incentivos fiscales, a la vez que presenta un nivel de IDH medio.

\section{Las Provincias Periféricas Rezagadas:}

a) Misiones, San Juan y Jujuy, jurisdicciones que el PNUD agrupa bajo el rótulo "Desarrollo intermedio con severas rigideces" (PNUD, 2002, p. 136-138). Se trata de provincias que se distinguen por un elevado grado de informalidad e inestabilidad laboral, por no registrar inversiones de grandes empresas y por un nivel bajo de Desarrollo Humano.

b) La Rioja, Santiago del Estero, Chaco, Corrientes y Formosa, caracterizadas por tener una "economía con un marcado retraso productivo y empresarial” (PNUD, 2002, p. 136-138). Estas jurisdicciones son las de menor desarrollo relativo del país y ostentan niveles bajos de desarrollo humano. Varias de ellas han empeorado su situación durante la última década. El aporte al producto nacional es insignificante o débil. El grado de informalidad laboral es alto y entre las actividades formales predomina el sector público.

c) Catamarca, que si bien presenta un cambio en su estructura económica derivado de la puesta en marcha de actividades mineras de gran envergadura, por el carácter de enclave que las caracteriza no ha tenido impacto sobre el resto del aparato productivo, y su IDH sigue siendo de los más bajos del país.

Para terminar esta sección, es preciso hacer notar algunas diferencias que se advierten en la presente etapa con respecto a lo que ocurría en la etapa anterior.

En el área central es donde se observa con mayor nitidez la concentración económica y la polarización social. La representación más notoria de estos hechos

resto de las que componen dicho grupo (PNUD, 2002). En este sentido, mientras algunos registros le asignan un lugar de transición, otros la muestran más cercana al grupo de Provincias Periféricas Intermedias que al grupo de jurisdicciones del Área Central. 
se da en la provincia de Buenos Aires, que si bien presenta espacios de consumo de altos ingresos también contiene bolsones de pobreza -en el llamado segundo cordón del Gran Buenos Aires; es donde los especialistas localizan los casos de mayor deterioro social del país.

En lo que era el Área Despoblada, el fin de las políticas de poblamiento ha generado una divisoria de aguas entre aquellas provincias que pueden hacer uso intensivo de la explotación de hidrocarburos respecto de aquellas en donde tal emprendimiento tiene un peso marginal. El caso arquetípico es el de la provincia de Río Negro, que presenta indicadores similares a los del área periférica.

En el caso de las Provincias Periféricas, las economías regionales han dejado de ser el elemento más determinante como línea divisoria entre los subconjuntos de jurisdicciones intermedias y rezagadas. Su posicionamiento en uno u otro grupo está relacionado con estrategias provinciales que permitieron una reconversión más o menos exitosa de sus economías regionales, más que con el papel que lograron asumir en una determinada división regional del trabajo ${ }^{19}$.

\section{Conclusiones}

Resulta evidente que la Argentina se caracteriza por ser un país con una notoria heterogeneidad y desigualdad territorial. Como hemos visto, esta asimetría ha sido común a todos los periodos de su historia.

Dentro de este panorama, a lo largo del presente trabajo se han subrayado ciertos elementos que muestran que las continuidades en el patrón de desarrollo regional han sido mayores que las rupturas. La preeminencia del área central se ha mantenido intacta en el último siglo y medio, más allá de los cambios en la estructura política, económica y social del país. De la misma forma, el retraso relativo de las provincias del Área Periférica no es una situación generada en los últimos años; por el contrario, se origina y reproduce desde larga data a partir de un conjunto de factores estructurales en continua regeneración.

19 Por ejemplo, Chaco y San Juan han pasado al grupo de Periferias Rezagadas a partir de una reconversión traumática de sus respectivas economías regionales.
Las importantes transformaciones que se inauguran hacia mediados de los '70 no modificaron sustancialmente este esquema. Sin dejar de reconocer los evidentes cambios en las especializaciones productivas y en los procesos sociopolíticos, todo parece indicar que las características que llevaron a describir el territorio nacional alrededor de tres áreas geográfcas se mantienen, e incluso han tendido a acentuarse.

En el tema que nos ocupa, el fin de políticas activas de desarrollo regional ha generado una serie de impactos particularmente notorios. En el caso de las provincias periféricas, se observa una crisis sin precedentes a partir de la desestructuración de las economías regionales, situación que ha sido parcialmente atenuada a través del incremento del gasto público. Sin embargo, este esquema no puede reproducirse indefinidamente, ya que el nivel de ingresos fiscales necesarios para continuar con el ajuste pasivo crece mucho más rápidamente que-crisis fiscal mediante- los recursos que puede transferirle el gobierno central a los Estados Provinciales.

De igual forma, en el Área Despoblada, el fin de las políticas de poblamiento y de gestión estatal del emprendimiento hidrocarburífero, como así también el creciente agotamiento de la ganadería extensiva, produce una serie de reacomodamientos que al parecer aún no han terminado. En los casos de las provincias con menores recursos petroleros, este proceso implica un corrimiento que las asemeja crecientemente a las jurisdicciones del Área Periférica; todavía queda por ver cuál será el decurso que seguirá el resto de la región.

En resumen, las políticas y el patrón de desarrollo productivo que se implantan a partir de la desestructuración de la ISI tienden a generar una mayor desarticulación territorial. Es lógico que tal variación en las políticas tienda a provocar mayores impactos sobre las áreas Periférica y Despoblada, donde las acciones del Estado tenían un papel crucial en la asignación de una función específica en la división territorial del trabajo. En este sentido, de no mediar importantes y profundos cambios, sólo podrá esperarse que los efectos polarizadores que tan claramente se observan en la estructura social se extiendan a lo territorial, profundizando la asimetría de las regiones que componen la República Argentina. 


\section{Referencias bibliográficas}

Arocena, R. (2001). Problemas del desarrollo en América Latina. Buenos Aires: Universidad Nacional de Quilmes.

Balán, J. (1978). "Una cuestión regional en la Argentina: burguesías provinciales y el mercado nacional en el desarrollo agroexportador". Desarrollo Económico, 18, 69.

Bolsa de Cereales (1999). Número Estadístico 1996/ 7-1997/8. Buenos Aires: Bolsa de Cereales.

Bolsa de Comercio de Córdoba (1998). Balance de la economía Argentina. Un enfoque regional. Córdoba: Bolsa de Comercio de Córdoba.

Cao, H. (2003). La especifidad del Estado y la administración pública en las provincias del área periférica de la República Argentina. Tesis de Doctorado, Facultad de Ciencias Económicas, Universidad de Buenos Aires.

(2006). "El sistema político regional de las provincias periféricas durante los ' 90 . Un modelo para comenzar a explicar causas y consecuencias". Realidad Económica, 206.

Cao, H. y R. Rubins (1998). "La cuestión regional y la conformación del Estado-Nación en la Argentina”. Cuaderno de Investigación CEPAS, 2. http://www.ag.org.ar/cepas.htm

Cao, H., R. Rubins y J. Vaca (2003). “Clasificaciones y agrupamientos de provincias y territorios de la República Argentina”. Cuaderno de Investigación CEPAS, 14.

Daus, F. (1975). El "subdesarrollo latinoamericano". Buenos Aires: Editorial El Ateneo.

Ferrer, A. (1980). La economía argentina. Las etapas de su desarrollo y problemas actuales. Buenos Aires: Fondo de Cultura Económica.

Gorostegui de Torres, H. (1992). La organización nacional. Buenos Aires: Paidós.

INDEC (1997). Encuesta de turismo internacional. Año 1996. Buenos Aires: INDEC, Ministerio de Economía.

Kulfas, M. y M. Schorr (2001). "Evolución de la concentración industrial en la Argentina durante los años '90”. Realidad Económica, 176.

Núñez, H. (1974). Indicadores de desarrollo regional en la República Argentina: resultados preliminares. Documento Interno No 10, Facultad de Ciencias Económicas, UNLP, La Plata.
OECEI (1974). La Argentina económica y social. Buenos Aires: Oficina de Estudios para la Colaboración Económica Internacional.

PNUD (2002). Aportes para el desarrollo humano de la Argentina/2002. Un enfoque integral. Buenos Aires: Programa de las Naciones Unidas para el Desarrollo.

Porto, G.G. (1995). “Convergencia entre regiones: algunos resultados empíricos para la Argentina 1953-1980". Porto, A. (ed.), Finanzas públicas y economía espacial (en honor a Horacio Núñez Miñana). Buenos Aires: Universidad Nacional de La Plata, Facultad de Ciencias Económicas.

ProvInfo (2005). Base de datos de la Unidad de Información Integrada. Buenos Aires: Ministerio del Interior, Secretaría de Provincias. http:// www.mininterior.gov.ar/provinfo/inicio.asp

Rofman, A. (1999). Las economías regionales a fines del siglo XX. Buenos Aires: Ariel.

Rofman, A. y L. Romero (1997). Sistema socioeconómico y estructura regional en la Argentina. Buenos Aires: Amorrortu Editores.

Salvia, A. (1997). La Patagonia privatizada: crisis, cambio estructurales en el sistema regional patagónico y sus impactos en los mercados de trabajo. Buenos Aires: Centro de Estudios Avanzados y Universidad Nacional de la Patagonia Austral, Universidad de Buenos Aires.

Secretaría de Agricultura, Ganadería y Pesca (1990). "Caracterización del sector agropecuario, provincia de Santa Cruz". Proyecto PNUD Arg. 85/019, $S A G y P$. Buenos Aires: Ministerio de Economía.

Statistics Canada (2003). Statistics Canada. www.statcan.ca

U.S. Census Bureau (2000). Current population survey. Washington: U.S. Census Bureau.

Vaca, J. (2003). "Articulación regional y desarrollo desigual en el territorio argentino". Territorios, 5 , 10.

Willington, M. (1998) "Un análisis empírico del crecimiento económico regional en Argentina”. Estudios, 21, 84.

Yanes, L. (1998). "El impacto territorial de la globalización". Programa de Políticas de Estado. Buenos Aires: Universidad de Buenos Aires. 